\title{
Managed Care Formularies: An Effective Tool?
}

Debate still rages over whether formularies enhance quality of care and reduce medical costs. What's clear is that this fundamental managed care pharmacy tool is continuing to evolve.

\section{II}

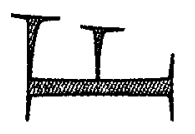

\section{CAROL SARDINHA}

CAROI SARDINHA is AMCP Director of Communications, Alexandria, Virginia. Copyright (O 1997, Academy of Managed Care Pharmacy, Inc. All rights reserved.
$\mathrm{P}$ ublication of a study by researcher Dr. Susan Horn in March 1996 sparked a new wave of debate regarding whether managed care formularies promote quality care and control health care costs. The study concluded that restrictive formularies correlated with higher utilization of medical services and greater costs. At AMCP's Educational Conference in Orlando, Peter Seaver, vice president of health care policy and advocacy with Pharmacia \& Upjohn, Inc., and Peter Penna, Pharm. D., vice president of managed care pharmacy with CIGNA HealthCare, discussed their personal views on the pros and cons of this fundamental managed care pharmacy tool and answered questions posed by the audience. 
The session, Managed Care Formularies: An Effective Tool?, was moderated by Suzanne Blackburn, R.Ph., Senior Vice President with Merck-Medco Managed Care, and held in presidential debate format. Topics addressed included formulary management and development, direct-to-consumer advertising of pharmaceutical products, OTC drug development, and the impact of Medicare and Medicaid beneficiary enrollment in managed care on pharmaceutical care This article recaps some of the session's highlights

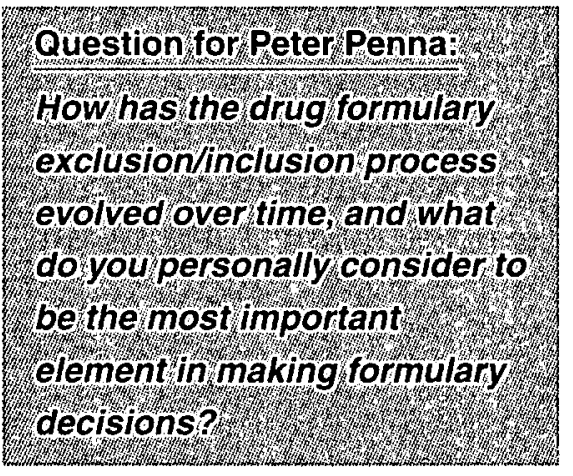

\section{Penna:}

I think the process has evolved from its roots in hospital pharmacy to the point where decisions are now made based on drug safely, efficacy, and, in some cases, costs or whether the drug is unique. To me, the single most important issue when evaluating a drug is its safety and effectiveness relative to other drugs that are out there. If those questions are answered satisfactorily, and if the product is not particularly unique, then I think cost can be a determining factor. But in my view, most effective P\&T committees need to base their decisions on safety and efficacy.

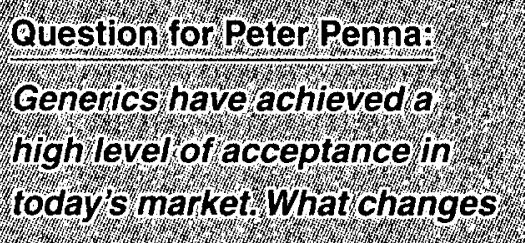

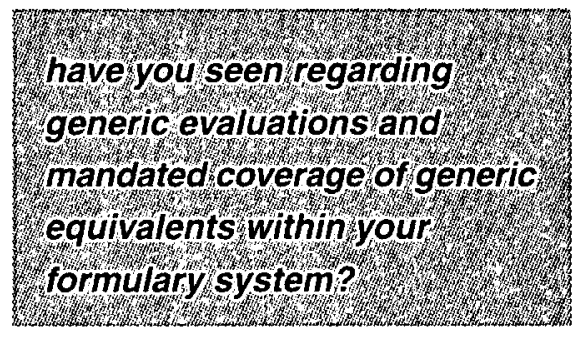

\section{Penna:}

Most P\&T committees don't evaluate generics differently than brand name products. Again, the important issues are the safety and efficacy of the product. There are concerns with generics about bioequivalence and overall equivalence compared to the standard benchmark brand name product. P\&T committees spend a lot of time trying to sort through such issues as: Does the product provide the same blood levels? Does it taste the same as an oral liquid? Is it suitable for a young child to take the product? Regarding mandated generic coverage, many plans are starting to require coverage of generics but will put financial incentives in place to give patients some choice. Patients might pay $\$ 5$ for a 30 -day supply if they choose the generic, $\$ 10$ for the brand name, or the difference in price between the brand name and the generic. There are a number of excellent generic products out there; and if the plan chooses them wisely, it can manage this component very well.

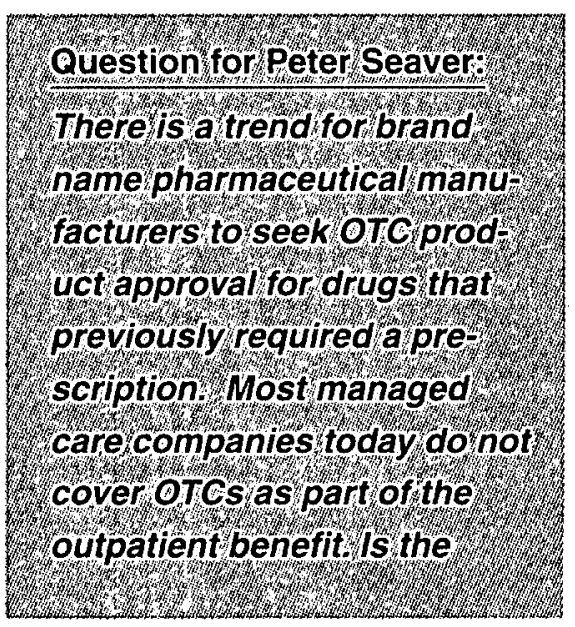

consumer s role as payer of these products driving oTC status change? And do you anticipate that managed care will start to manage use of OTCs and include them in the tormulary process?

\section{Seaver:}

The role of the consumer is pivotal as we look at the life cycle management of these products over many decades. But it isn't just the consumer as payer that's driving it; it's that we have learned to refine the technology to the extent that it virtually can be universally applied where needed. What's different in our strategic planning process, and bodes well for what I think must happen in managed care, is that we have to begin developing these products early on with the full understanding of what the future needs of the consumer will be. We have to make that attractive enough so that the managed care plan will give incentives to the plan member, the patient, to make full use of that technology when it gains over-the-counter status. This is a terrifically exciting time Just look at what has happened with the $\mathrm{H} 2$ antagonists (anti-ulcer medications) within the last year. Some of you may cynically say, "Look at all that wasted money on these television ads." But the fact is, these are making a tremendous impact on the digestive health of the country. And I do believe that it is saving enormous amounts of money in the process and putting the consumer in the driver's seat.

Question for: Peter Penna:

The tool lbox managed care pharmacy has created to op timize patient care in a cost 


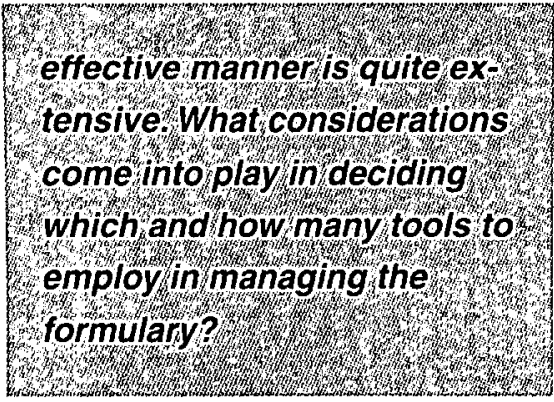

Penna:

Which tool one uses depends first on the drug or the drug class we are talking about. I would choose a different tool if I were interested in managing antidepressants than if I were managing antibacterials. Second, you have to look at who your target audience is, such as whether it is a group of primary care physicians or a specialty group. Third, you need to look at your patient population. In some cases, using patient educational materials may be very appropriate, but in some cases they may be virtually worthless. As for deciding how many tools to apply simultaneously, I think that's a function of how difficult the task is going to be, and how much. feedback you expect in terms of improved quality, decreased costs, or whatever outcome you're seeking. If it's a relatively straightforward therapeutic interchange, such as switching from one ACE inhibitor to another, maybe sending some letters to physicians identifying their patients on the drug, providing some informational materials for those physicians and their patients, and making personal visits with the physicians might be all it takes to get things rolling. If you wanted to deal with SSRIs, however, doing just those things I mentioned isn't going to cut it. In that case, you might have to go so far as to do research to justify the position you want to take.

\section{Peter Seaver:}

I would like to amplify on that question regarding formulary tools. I still feel there's a need to look not just at overall costs but overall well-being of the patient. What about the mother with a full-time job who has to go to the same clinic twice a week with the same child with otitis media for four weeks in a row because every time she goes, she has to dance around with the generic ampicillin that was not effective 15 years ago for that kind of bug? I am exaggerating here for effect, but that's the kind of thing I'm concerned about. So when we start selecting tools and determining how many and what kind of tools we need, we have to be keeping her in mind.

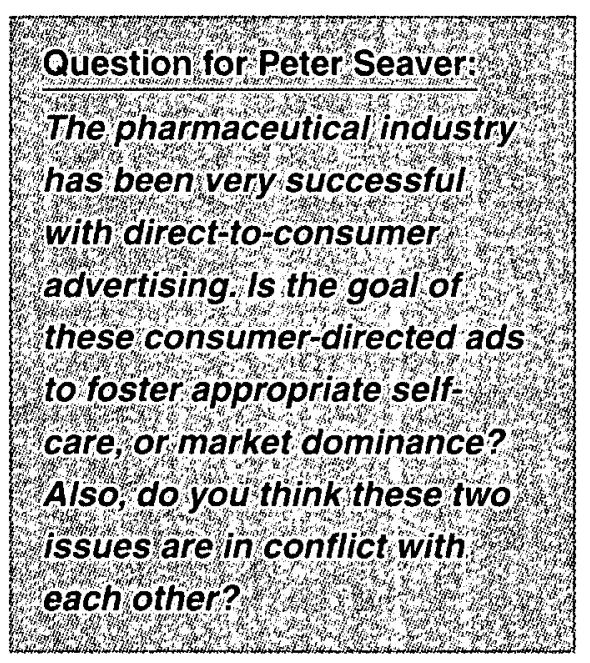

\section{Seaver:}

I think some of us would agree that the industry has been successful with these ads. The secret to good direct-toconsumer advertising, of course, is to narrow the audience down to those who really need the information. Once that is on the plate, then the driving force behind these is the knowledge of the patient. Now if you are the steward reporting to the company's board of directors and you have to talk about managing the life cycle of this particular product once it goes over-the-counter, then of course you'd like to have market dominance, or at least make sure people cannot think about that drug category without at least having your brand or something favorable about your product pop into their minds.
Now, whether that is palatable or not to managed care plans, I do not know. We actually have gone to some plans in markets where we have targeted regional advertising and said that if you offer this product under your plan, you may see increased enrollment because the drug will appeal to consumers. We have had very limited success there so far, but I think that's the kind of thing we are going to see in the future.

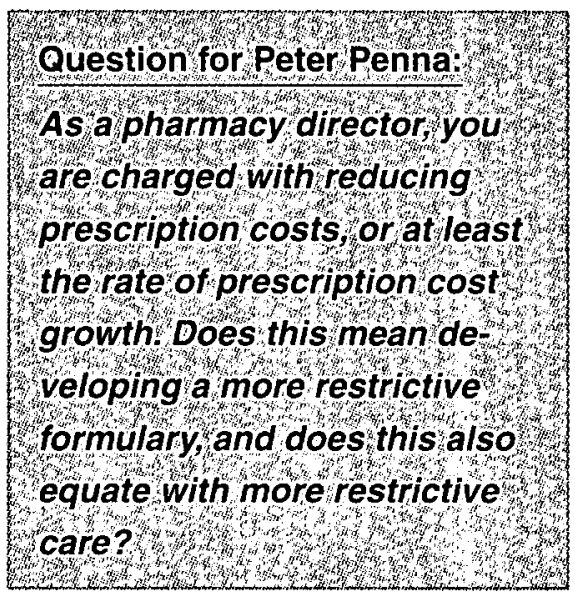

\section{Penna:}

There are those insurance bureaucrats out there who truly believe that you need to make the individual numbers smaller in the individual silos, and they do not care that by denying a vaccine or a breakthrough drug, it increases costs elsewhere. They are just worried about this quarter's profits or next month's financial report. However, I think more people in managed care are starting to take a broader view. But before they go forward and say, "go forth and spend," they are going to ask for some pretty tough information. They are going to want to know that what you are doing is the right thing. They will want proof, and they will want evidence.

In terms of restricting the formulary, I know that if I cut my formulary from 1,000 drugs down to 700 , I am probably going to reduce my pharmacy costs. But after a year, if people begin leaving the plan because of ill-conceived ways

Continued on page 29 
of managing things, that loss will probably far outweigh any savings I may have gained. I think intelligently applied with the right population, and with the right benefit design, a restrictive formulary can work wonders. And there has to be an exception to take care of the patient for whom the conventional wisclom of the organization simply does not apply. It is easy to say all ACE inhibitors are virtually interchangeable, but we do know there are those patients who respond better to one drug versus another. If their drug isn't on the formulary, it makes sense to have a process that will enable them to have access to it.

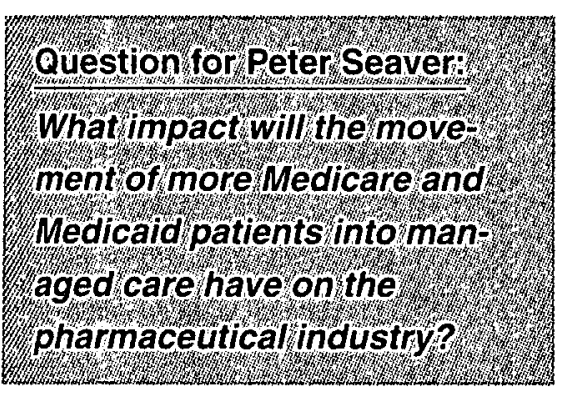

\section{Seaver:}

Both my parents are 83 and healthy, on multiple drug regimens, and outliving their previous generation by decades because of the availability of these medicines. Yet they express disbelief and bitterness over the costs associated with these therapies. I think as managed care plans begin to bring these people on board and provide access to prescription drugs, it bodes well for us.

I do want to say, however, that the request made to the pharmacy director to reduce his or her spending is an inappropriate one, even though $\mathrm{l}$ know the reality is that you have to face it every day. Yes, you will get to keep your job for another year as a pharmacy director. The bad news is you have got to treat more patients with fewer funds next year. The mission here should be to enlighten the individual who is making the request. And it is not just based on the old argument that only $7 \%$ of the health dollar goes to prescriptions.
It's because every single day another 50,000 people turn 65 in this country, and that means there are just going to be more expenditures. And the ACE inhibitor that's right for my mother is not the one that's right for my father, and they need to have the one that's going to control their blood pressure to allow them to have the quality of life they deserve.

It can't just be the pharmaceutical industry that says it's inappropriate. If the profession of pharmacy is going to hook itself to the wagon of managing just this component of the whole ball game, then I do not think we need to have the legions of bright people flowing into the profession today that we have. And that doesn't bode well for people like my mother 20 years from now. We are counting on your profession, and we have an obligation to give you the outcomes data so you can help us do that job.

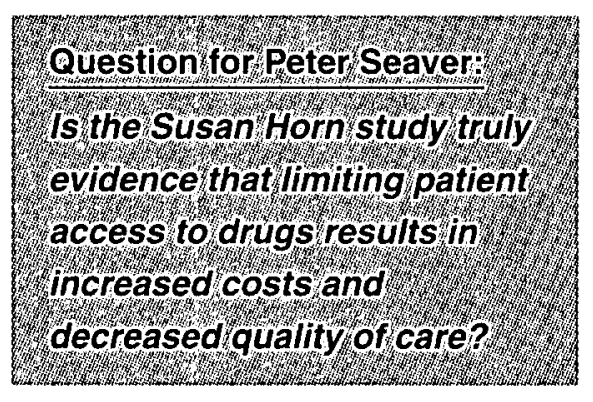

\section{Seaver:}

The study, despite its shortcomings, did come to the conclusion that the greater the rate of restrictiveness, the greater the overall utilization of services, and thus costs. This is not the definitive work, and it does not prove this for all time. It was a random selection of health plans. But I see the study as a bit of a wake-up call, only in that it teaches us that rules need to be modified and upgraded as we get more and better information. As I look at the study, I get the feeling that some patients in some disease states may be getting consolation prizes compared with what they could have had in other health care plans. 1 think it is a call for action for us to get together and move forward together to do additional studies.

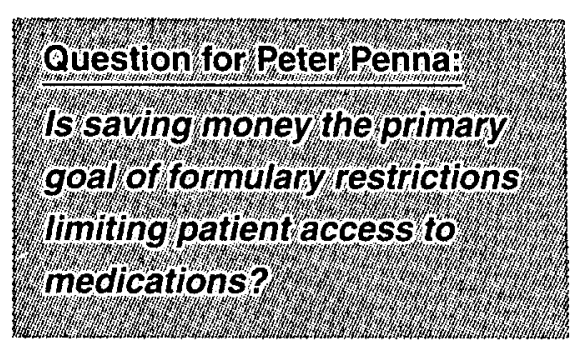

\section{Penna:}

That answer depends. I think some plans are all about managing costs rather than managing care. I think that their futures are going to be short lived because at some point, all the costs are going to have been wrung out of the system, and then competition will be based on quality. And the plan that can document the best quality is going to be the winner in the long run.

The formulary in our plan has a dual purpose: to control both quality and costs. I have a fiduciary responsibility to make sure that the plan, and employer purchasers of the plan, are spending their money well. The best employer groups out there are asking some very tough questions of us in terms of what outcomes we produce, what we are doing to control polypharmacy and drug interactions, and what we are doing to assure patient compliance. If an employer asks why his or her expenditures for lipid-lowering drugs are so high, we investigate and try to answer those questions. In some cases with lipid-lowering drugs, we have found that they, in fact, should probably be spending more. And while they did not like that answer at first, when they thought about it, they look the big picture approach and looked at it from the standpoint of doing what's best for our patients. If we run the formulary system right and take into account the things that we need to be doing, we will improve quality and control costs, though it is a very tricky thing to do. 